\title{
Successful PR-support means concerning the public image and business reputation of the corporate press
}

\author{
Anna Belkova ${ }^{1, *}$ \\ ${ }^{1}$ Nizhnevartovsk State University, Academic Department of Philology and Mass Communication, \\ 628602, 56 Lenina str., Nizhnevartovsk, Russia
}

\begin{abstract}
This article covers the PR-support of the public image and business reputation using the example of the corporate magazine "Oilfield Review"; this magazine belongs to Schlumberger - an oilfield services company. Schlumberger is an international supplier of technologies concerning the development of program products for oil and gas exploration, oil production and geophysical research. Among many other regions, Schlumberger operates in the Khanty-Mansi Autonomous Okrug as well. Considering the aspects of corporate press, it is worth noting that a special emphasis has to be put on the «effectiveness» criterion. Efficiency of resource application of corporate mass media and its ability to reach the goal of corporate communication project, this is what has to be understood under the term of «effectiveness». Corporate press is the means of outreach activities aimed at the public opinion of different types of groups within the company, that includes: employees, business partners, customers, governmental authorities and so on. The indirect commercial link between the cost of publishing of corporate media outlets and the increase in revenue of the company arises through the activities of the target audience. The effectiveness of PR-support of public image and business reputation of corporate press is measured by the quality and effectiveness of the process results aimed at the target audience. The effectiveness of PR-support is measured by the following criteria: the level of demand for corporate publication; the level of understanding of the information by the public; the level of information impact on the private opinion of the readers concerning the activities of the company; the level of information impact on the behavior of the intended readers. This article concerns the consecutive evaluation of a Schlumberger corporate media outlet «Oilfield Review», its PR-support effectiveness in the following aspects: its structure, design, the quality of the articles, the quality of the pictures, the level of interactive technologies, and the system of key messages.
\end{abstract}

The PR-support of a media outlet is an expensive investment project that ensures the constant presence of the said media outlet in the media space. The PR-support of public image and business reputation has its key features that ensure the success of a corporate

* Corresponding author: bae14@mail.ru 
media; these features include: the content of the print media, its quality as well as its utility for the target audience. This research follows the method proposed by Agafonov L.S., the method of express-evaluation of the media outlets effectiveness [1-2].

This article examines the corporate magazine «Oilfield Review» as the means of brand positioning of oilfield services company Schlumberger, using the consecutive evaluation of the press media by the features of PR-support effectiveness. The pattern of directed impact on the target audience as follows: the structure of corporate media outlet, its design, the quality of the articles and images, the level of interactive technologies, and the system of messages. The analysis of the aforementioned features is listed below.

Structure (subject heading list, topic balance). Corporate magazine «Oilfield Review» is structured. The consistent composition consists of the following features: [front page] + [historical reference] + [annotated table of contents] + [articles of the magazine] + [information about the writers].

The content of Schlumberger «Oilfield Review» corporate magazine is always oriented towards the features and the sector the company operates in. For example, the issue of «Oilfield Review» magazine (winter 2014 - September 2015) contains the following articles: Unlocking the Potential of Unconventional Reservoirs, Reducing Uncertainty Ahead of the Bit and so on. [3].

Outer appearance of the magazine (design, typography, visualization). The magazine «Oilfield Review» is published on A4 paper size, the articles contain three (less often two) columns. The following features are common for this corporate magazine:

- Balanced articles feed (the language in the articles is measured, has a calm manner): «Ekofisk oil field is located on Norwegian Offshore Continental Shelf, this oil field was found by Phillips Petroleum Company in 1969 and was placed on production in 1971» [3];

- Constant graphical model is presented through the implementation of the topic model with consistent and permanent graphical, typographic and pictorial means. Different typefaces are present in «Oilfield Review» magazine; text type as well as title type and display typeface. All the typefaces are easily readable and rich in contrast. The different corpus size of headline letters and the main text of the article.

- The sufficiency and profusion of the graphical set (which may vary from the standards), without a strict degree of consistency (in some cases an illustration gets the central place on the page instead of the text);

- Different types of form and content in the headlines (modest headlines are present on a more frequent basis. Compare the headlines: Sand Screen Modeling and Selection; Multiphase Flow Simulation - Optimizing Field Productivity. Emphatic and attractive headlines appear less often: Shushufindi - Reawakening a Giant) [3-4];

- Vertical page makeup (all the articles are placed vertically, vertical sections on pages make one's eye move up-and-down thus preventing the reader from a satisfying information perception);

- The combination of text with attractive illustrative material;

- Contemporary glossy design

- Architectural photography, documental delivery with the photographs of outer look or certain details of an architectural object; wide-angle lens are used in order to achieve a wider scope of an image. As an example, there are photographs of a platform for personnel responsible for production of pumping and drilling operations, wellsite production processing as well as other tasks on the hub on North Sea oil field.

- Photojournalism (news photograph captures different events from local to global scale ones; this type of photography requires a quick composition formation by the photographer and also it requires an immediate reaction as the situation changes);

- Portrait photography (a picture of a person or a group of people that do exist in the reality by the means of photography). Rectangular type of photography with portrait and 
landscape formats is used in the magazine «Oilfield Review». Portrait format is used for a one-man portrait, and it is the most well-known format of all the formats. Landscape format is used for a group portrait, less often for a one-man portrait. Portrait photography is deemed to be the most difficult type of photography. A great set of knowledge and abilities is required from the photographer. The main goal of portrait photography is to transmit all the features of a person, their look as well as their life experience. Experimentation with reflections, tricks of the light, camera adjustments - it all assists to take photographs that are able to draw attention of the readers of corporate magazine «Oilfield Review».

- Significance of different types of diagrams - plane diagrams with text and communication features. Illustrated graphical means is the visual display of organization of different things. The diagrams in this magazine have captions in the same way as pictures do, the diagrams are numbered as well as the other pictures; the diagrams are placed below the text. There are different types of diagrams in the magazine: general diagram, schematic diagram, operating diagram and location diagram;

- The consistence and precision of the tables present the graphical form of quantitative data in a succinct format (there are simple tables, group tables, cross-tables and multilinetables; tables are referenced in the main text of the article, the tables have their own titles).

- The quality of the articles (genre system, topic correspondence, consistency, stylistics, grammatical correctness). It is indisputable that the key component of this magazine is its content. The presentation of the informative part of this magazine is defined by the following factors: the size of the magazine (it varies from 80 to 100 pages, one the average there are 5 to 8 articles per issue), the space (an article takes up 2 to 3 pages) and the timeframe (the magazine is issued once every four months), these factors are the components of text and illustrative material.

The magazine «Oilfield Review» is published by Schlumberger in order to provide an insight into the engineering achievements in the field of prospecting and production of hydrocarbons for its employees, business customers and other oil and gas industry specialists.

The articles are written in understandable language formats, the articles also have a consistent style. The topic model of the corporate magazine is represented by the selection of articles from «Oilfield Review», the articles from this selection are translated into Russian. The translations from the source publishing are of high quality.

The main subject of the magazine is assorted as the articles are presented in different orientations: business-related, data and industry-related. There are different topics in the magazine concerning the issues of a region's economy, energy efficiency, environmental safety, development of oil industry, field development, business culture and so on. The magazine serves the interests of its target audience by providing an insight into the technological and engineering innovations; the magazine promotes advanced experience and serves as a means of internal discussions concerning the approaches of corporate policy.

The conducted analysis of the magazine «Oilfield Review» reveals the typological characteristic of the corporate press genre.

The corporate media outlet is a two-way communication channel of information between the employees and the company management, as well as it is a PR-related means of the company. The corporate media outlet publishes articles in the genres concerning the public relations:

- News-focused genres (an invitation, an image-building article, an interview) - 35\%

- News-research genres (a backgrounder, questions and answers form, a rating, monitoring, a review) $-30 \%$

- $\quad$ Fact-based genres (a fact sheet, a biographical statement, chronicle) - 15\%

- $\quad$ Research genres (a press statement) - 5\% 
- Presentative-oriented news genres (a by-liner, a congratulations message, a public service message, a newsletter, a recommendation) - $2 \%$

- Media texts (an image-building interview, an image-building article, a case story) $10 \%$

- $\quad$ Related texts (an advertising slogan, a summary statement, a press release) - 3\% [5].

The classification of the aforementioned genres by groups has revealed that most of them belong to the news-related genres as well as to the analytical ones, i.e. narrative nonfiction genre is not common in the corporate press. It is worth noting that the corporate outlet «Oilfield Review» is a combination of news and communicative aspects of journalism and PR.

The quality of the illustrations (informative value, quality, design, correspondence with the illustrated object). The images that are presented in the «Oilfield Review» magazine support, complete and graphically demonstrate the main text of the articles. The pages of this magazine feature high quality colored graphic art of photographs, illustrations, tables, diagrams and charts. The main goal of these illustrations is to better the information perception, and to assist the process of reading. The illustrations in this magazine are accompanied by different decorative features (tailpieces, initial letters, descriptive annotations). The illustrations are professionally done and processed in a qualitative manner on the preprint phase.

The informative value of the illustrations is enhanced by the usage of such features as: indicating arrows, text highlighting, picking out specific items, exaggerated statements, captions and annotations. The listed features are frequently used in the «Oilfield Review» magazine, for example, the annotations contain a part of the key information of the article. The serial-position effect is used in order to position the illustrations.

The analysis results of the positioning effectiveness indicate the usage frequency of the first and the last items of the illustrative information. The frequent usage of the right side of the illustrative arrangement must also be noted.

The "Oilfield Review» uses the effect of color impact in order to enhance the attractiveness (the squares are blue, purple and yellow; the vertical rectangles are yellow and green; vertical ellipses are red and purple).

The photographs in this magazine are placed at the top of the page, as the eye moves from top to bottom, from the left to the right, diagonally. This type of positioning makes it possible to control the eyes of the reader, to attract the reader's eye to the main point of the illustration.

The writers of this corporate media outlet take into account the specific nature of human perception, and thus they use different means to place an emphasis on the important words and phrases, for example, text highlighting, they change the fonts when it is necessary, underline the information, use capital and lower-case letters. A visual contrast appears when the font size diversity is introduced. This contrast is used in order to differentiate the interest priorities: the bigger size font is for the key elements, smaller font is for the secondary information. With regard to this, the bigger body-size of the letters is used for the headlines so that it attracts the attention of the reader firstly, and the smaller body-size of the letters is used for the main text of the article. In order to place an emphasis on the headline, the bold type is used as the means of stressing to attract the attention to a significant amount of words. Semi-bold type of blue color is used in order to put an emphasis on the abstract that precedes an article.

The level of interactive technologies (the presence of interactive means, the level of the feedback impact on the magazine). The magazine represents the information imparting by the Schlumberger management team, therefore there are no special services for the feedback (except for the "Contact Us" reference on the company's website, which is an inquiry form for additional information). 
The term «feedback» has become one of the key elements of personnel management as well as of the improvement of the effectiveness of corporate culture. Properly built feedback channels make it possible for the management to get up-to-date information concerning the managerial decisions, correct the work of different employees and the entire branches.

Considering the aforementioned information, the exchange should be fair and mutuallybeneficial for the management team and all the employees: the management team receives the information to adjust their further actions, and the employees receive both criticism and encouragement. Currently, the following means of the feedback are getting more popular:

- Services for online-calls on the website, a call can be made using a computer;

- Consulting Online Expert, works as a popup window and all the communication is done through the text chat

- Inquiry forms offering callback from the company and live chats; as well as the callback-widgets where the user can enter their phone number.

With regard to this, the magazine «Oilfield Review» needs to maintain the two-way interaction, i.e. the information must be exchanged between the management team and the employees of the company. Given that there is a feedback, the sender and the recipient exchange the communication roles.

System of the key messages (messages structure, the quality of their delivery, the balance, the level of reasonableness). The system of brand values can be seen in the «Oilfield Review» magazine. Schlumberger determines its key values of the corporate culture as «we are a team», «we are the best». The archetype of an ideal employee of Schlumberger that matches the company's corporate culture can be described with the following phrase «I enjoy my work».

The inputs of outside mediators are well represented: professionals and experts of oil and gas industry from all round the world, as well as the employees of the company and affiliated companies share experience and knowledge. The inputs of the following experts are presented in the magazine:

- Intan Azian Binti Abd Aziz - Head of Well Delivery of the Petronas Carigali Sdn Bhd, Malaysia, Kuala Lumpur

- Zheng Gang Xu - Schlumberger Advisor of OLGA Dynamic Multiphase Flow Simulator Development, Norway, Kjeller

- Sherman Yang - Head Geoscientist of the Wellfield Center in China, Beijing

- Andrew Zheng - Surface and Subsurface Integration Architect at the Schlumberger High Efficiency Center of Excellence in Katy, Texas.

- Dmitriy Usoltsev - Schlumberger Product Champion for Diversion and Acid Stimulation Services in Sugar Land, Texas.

- Hua Yang - Deputy Head of the Petro China Changqing Oilfield Company, Xian, China

- Kevin Wutherich - Schlumberger Expert of production stimulation in the Northwest USA, Canonsburg, Pennsylvania

- Fernanda Tellez Cisneros - Schlumberger Senior Design Engineer for matrix acidizing, acid fracturing and hydraulic fracturing in Villahermosa, Mexico.

Schlumberger concept of development in Russia and Central Asia is about being a prioritized business partner of all members of oil and gas industry, the members are producer companies, science foundation, educational and government facilities. The company strives to reach this goal by actively cooperating and giving inputs into the stable development of regional and national infrastructure and economy.

Schlumberger:

- Conducts business activities in accordance with Russian legislation in the matter of industrial and occupational safety; 
- Follows the international Schlumberger standards in the matter of business integrity and information security of the customers;

- Conducts procedures for environmental protection, minimizes the environmental impact and adheres to the environmental protection legislation.

- Supports the initiative of improving the quality of life in the regions where the company's employees work and live in;

- Invests into the operational staff, infrastructure, production assets and Research and development, the company also trains local suppliers and business partners.

Schlumberger business function is based on the values and the code of business conduct:

1. The services provided by Schlumberger to its customers ensure the achievement of great results by utilizing the specific resources of the company to their full advantage. Company's work is based on the three unchangeable values: highly-skilled employees, modern technologies and the striving for high profit of the business.

2. The strength of the company is in the ability of the personnel to succeed in any activity, in commitment, safety and the high quality service delivery to the customers from all around the world. The main priorities that give Schlumberger competitive advantage are the modern technologies and high quality service. An aim to work, receiving high profit is the keystone of growth and self-support in the future.

3. Schlumberger strives to reach the perfection in every field of activity. The company works with every customer based on the principles of consistency and transparency, Schlumberger does not hold any stocks of shares of its business customers. The customers trust Schlumberger, especially when they deal with valuable or confidential information. The reputation of a responsible and fair partner is a major factor of gaining and keeping confidence of the customers.

Schlumberger strives to keep the confidence of its customers and shareholders as well as the confidence of all those who are related to the operational activities. The company clearly demonstrates its adherence to the ethical standards, maintaining the reputation of a fair partner that contributes to the attraction and maintaining of the customers and employees.

4. Schlumberger adheres to the principles of a good corporate governance. The practical aspects of corporate management are implemented into the company; these aspects promote the effective work of Board of management, its sections and the company in general.

5. The principle of ethnic and cultural diversity. The company employs men and women of different nationalities and cultures, united by common goals [6].

In summary, this article covered the «Oilfield Review» magazine from the standpoint of PR-support of public image and business reputation of the corporate press. The analyzed magazine is related to the corporate media outlet for all the employees. By the level of sufficiency on the preparation and issue phases, this magazine is outsourced and published with the assistance of outside specialists. The main goal of corporate magazine «Oilfield Review» is the brand positioning of Schlumberger Company.

According to the presented results, the effectiveness level of this corporate media outlet is at $85 \%$. The "Oilfield Review" magazine of the Schlumberger oilfield services company is a high-quality example of a professionally done product that services its target audience by using effective means of PR-support. It is worth noting that the further improvement of the effectiveness up to $90-95 \%$ can be conducted by adding the following means of PRsupport: a special service of feedback should be created in order to better the cooperation and the performance of the employees.

The system of PR-support means of public image and business reputation of the "Oilfield Review" magazine is presented at a high level. This determines the main values of the corporate culture: "we are a team," "we are the best," "I enjoy my work." 


\section{References}

1. L. S. Agafonov, Corporate press: features of functioning, typological characteristics and efficiency evaluation method (2008)

2. A. E. Belkova, Scientific Notes of the Orel State University, 390, 92 (2017)

3. Oilfield Review, 108 (2014)

4. Oilfield Review, 92 (2015)

5. E. A., Belkova, A. Y. Belobrova, Derivational structure of oil and gas terms, formed by an attribute model of addition. Scientific journal "Young scientist", 954, 871 (2016)

6. https://www.slb.ru/about/guiding_principles/ 